\title{
A Preliminary Investigation of Diffusion of Volatile Atmospheric Acids in Snow
}

James H. Cragin and Daniel C. Leggett

November 2003

US Army Corps of Engineers ${ }_{\circledast}$ Engineer Research and Development Center

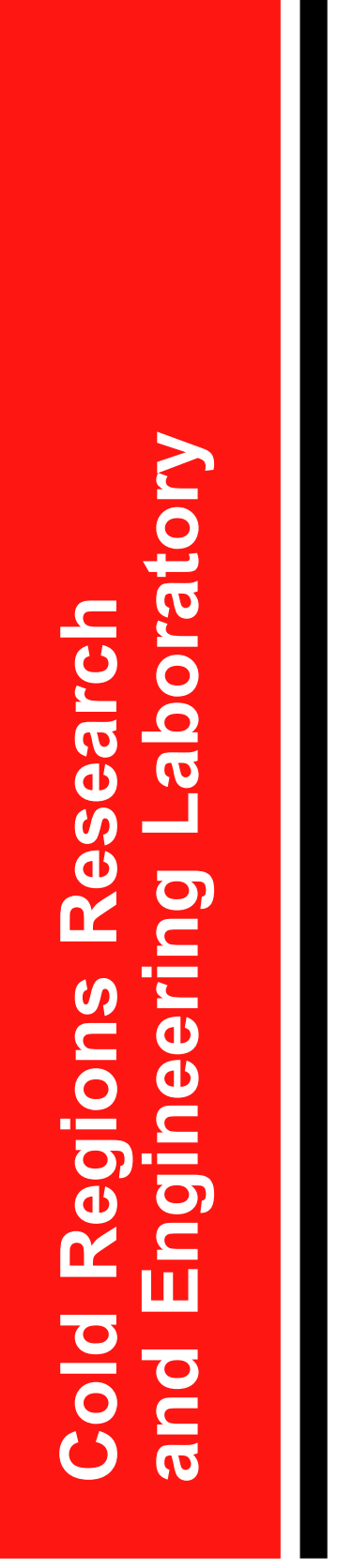


ERDC/CRREL TR-03-22

November 2003

\section{A Preliminary Investigation of Diffusion of Volatile Atmospheric Acids in Snow}

James H. Cragin and Daniel C. Leggett

Cold Regions Research and Engineering Laboratory

72 Lyme Road

Hanover, New Hampshire 03755

Approved for public release; distribution is unlimited. 


\section{ABSTRACT}

A preliminary coldroom experiment was conducted to determine the diffusion rate of several reactive atmospheric chemical contaminants in snow at $-7^{\circ} \mathrm{C}$. These species included formaldehyde, $p$-nitrotoluene (PNT), $\mathrm{HNO}_{3}$, and $\mathrm{HCl}$. Because of detection or contamination problems we could not quantify diffusion rate for formaldehyde, $\mathrm{PNT}$, or $\mathrm{HNO}_{3}$. However, the diffusivity of $\mathrm{HCl}$ in snow $\left(\rho=0.38 \mathrm{~g} / \mathrm{cm}^{3}\right)$ was found to be $>7.7 \times 10^{-4} \mathrm{~cm}^{2} / \mathrm{s}$. This is about two orders of magnitude greater than hitherto expected and suggests that $\mathrm{HCl}$ may be rapidly redistributed or lost from seasonal snowpacks. Thus, one should be cautious in interpreting temporal records of $\mathrm{HCl}$ and other volatile species in seasonal or polar snowpacks, until their integrity is better established.

DISCLAIMER: The contents of this report are not to be used for advertising, publication, or promotional purposes. Citation of trade names does not constitute an official endorsement or approval of the use of such commercial products. All product names and trademarks cited are the property of their respective owners. The findings of this report are not to be construed as an official Department of the Army position unless so designated by other authorized documents. 


\section{CONTENTS}

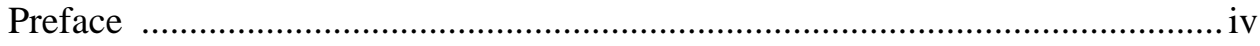

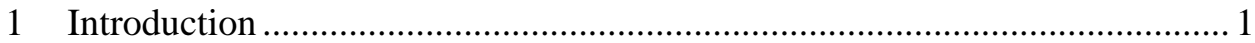

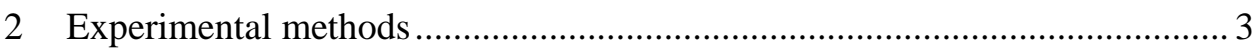

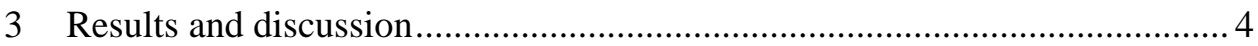

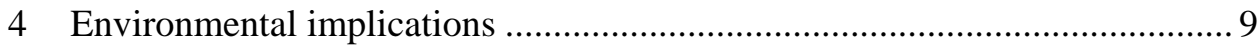

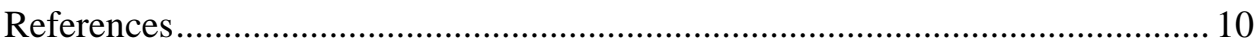

\section{ILLUSTRATION}

Figure 1. Chloride concentration in snow versus distance from the source......... 5 


\section{PREFACE}

This report was prepared by James H. Cragin, Research Chemist, Snow and Ice Branch, U.S. Army Engineer Research and Development Center (ERDC), Cold Regions Research and Engineering Laboratory (CRREL), Hanover, New Hampshire; and by Daniel C. Leggett, Research Chemist, Environmental Sciences Branch, ERDC-CRREL.

Funding was provided by ERDC/CRREL.

The authors thank Dr. Samuel Colbeck and Dr. Matthew Sturm of CRREL for technically reviewing the manuscript.

The Commander of the Engineer Research and Development Center is Colonel James R. Rowan, EN. The Director is Dr. James R. Houston. 


\title{
A Preliminary Investigation of Diffusion of Volatile Atmospheric Acids in Snow
}

\author{
JAMES H. CRAGIN AND DANIEL C. LEGGETT
}

\section{INTRODUCTION}

Trace constituents of the atmosphere can contribute to important processes such as ozone destruction, acid precipitation, and global warming. It is important to understand the sources and fates of these compounds in order to assess the role of man's activities on these processes. Some trace species that have been implicated are the mineral acids hydrochloric, sulfuric, nitric, and low molecular weight oxygenated species, formate, acetate, formaldehyde, sulfur dioxide, and hydrogen peroxide. These species are very soluble in water and are efficiently scavenged and dissolved by small water droplets in the atmosphere. When these droplets are quickly frozen, as often occurs in the atmosphere, the trace species are "frozen in" (Iribarne and Pyshnov 1990) at concentrations exceeding their equilibrium solubility in ice.

Permanently frozen precipitation may then serve as a semi-permanent record of historic atmospheres, and polar ice core analysis could be used retrospectively to establish past conditions. One may doubt this conjecture, however, as volatile species would be expected to redistribute over time so as to achieve local ice/air equilibria. We would expect these changes to be reflected in temporal changes in volatile species concentrations in snowpacks, and, in fact, these kinds of changes have been observed in mid-latitude snowpacks (Hogan et al. 1985) and in laboratory-stored snow (Cragin and McGilvary 1995). The kinetics of redistribution processes and the ultimate fate of various contaminants remain obscure, however.

Contaminants also enter snowpacks by dry deposition on the fallen snow. This applies not only to atmospheric sources but to sources such as soil beneath the snow. Because of the prevailing temperature gradients, volatile contaminants tend to accumulate in the coldest snow, which is often the top of the pack (Hogan et al. 1985, Hogan and Leggett 1995). Because these phenomena are hard to study in nature, most of our information comes from laboratory investigations. 
However, no direct information on diffusion of trace volatile species in snow was found. Diffusion of solute vapors through a porous medium such as snow is expected to be retarded with respect to vapor movement in air by interaction with the media and tortuosity effects.

Available information suggests that interaction of acidic species with ice particles is strong, and that diffusion into the bulk ice occurs. The diffusivities of hydrochloric and nitric acids from dilute vapor sources in ice have recently been estimated. The reported values range from about $10^{-12} \mathrm{~cm}^{2} / \mathrm{s}$ at $-8^{\circ} \mathrm{C}$ for ice single crystals (Domine and Thibert 1995) to around $10^{-8} \mathrm{~cm}^{2} / \mathrm{s}$ for polycrystalline ice (Diehl et al. 1995). The latter value would presumably be more relevant for atmospheric studies and for the work reported here since snow is essentially unconsolidated polycrystalline ice. If so, we would anticipate essentially complete permeation of the ice spheres during the time course of our experiment, although complete equilibration with the ice lattice could take years, assuming the lower diffusivity.

To avoid complicating effects of temperature gradients, we used a single isothermal temperature for this preliminary study of dilute vapor migration through snow. Compounds initially selected for study were $\mathrm{HCl}, \mathrm{HNO}_{3}$, formaldehyde, and p-nitrotoluene. The latter was added as a reference compound as one of us had successfully used it before in outdoor, temperature gradient experiments (Hogan and Leggett 1995). 


\section{EXPERIMENTAL METHODS}

All laboratory work was performed in a Class 100 cleanroom or Class 100 clean air station in a coldroom. Because of the finite background concentrations of many atmospheric species in natural snow, we prepared clean artificial snow from frozen Milli-Q deionized water as described below.

First, we added Milli-Q water to pre-cleaned 7.5-cm-diameter polyethylene tubes that were heat-sealed on the bottom. Leaving about $20 \mathrm{~cm}$ of air space for expansion above the $60 \mathrm{~cm}$ of water, we sealed the top and slowly $(1.8 \mathrm{~mm} / \mathrm{hr})$ froze the water vertically by lowering it into a circular opening in a freezer (see Cragin and McGilvary [1995] for a more detailed description of the apparatus and process). We sliced the resulting ice core into 1-cm-thick sections and rinsed them in Milli-Q water to remove surface contaminants and then mechanically crushed the sections in a pre-cleaned Plexiglas chamber (similar to a mortar and pestle).

We sieved the resulting snow so that the 0.425 - to 0.850 -mm-size range fell naturally through a funnel into a 10-cm-diameter Plexiglas column. We suspended separate 1-mL vials of formaldehyde, $0.1 \mathrm{M} \mathrm{HCl}, 0.1 \mathrm{M} \mathrm{HNO}_{3}$, and PNT in the airspace above the snow and finally sealed the column with an airtight cap. Vapor was free to move within the chamber from the uncapped source vials to the snow. We left the apparatus in a coldroom at $-7^{\circ} \mathrm{C}$.

After one week we opened the column, removed the source vials, and sectioned the snow core crosswise in a clean air station in the coldroom. The resulting 1- or 2-cm-thick wafers were melted and analyzed. Analyses for formaldehyde and PNT were done using gas chromatography while chloride and nitrate were determined using ion chromatography. 


\section{RESULTS AND DISCUSSION}

We failed to detect p-nitrotoluene (PNT) in any of the snow samples. This was somewhat surprising because it had been detected in earlier work (Hogan and Leggett 1995) in snow over PNT-spiked soil at a similar temperature and using the same method of analysis. The difference was that the earlier experiment was conducted outside in the presence of a strong temperature gradient, so that the source was at a higher temperature $\left(\sim 0^{\circ} \mathrm{C}\right)$ compared to $-7^{\circ} \mathrm{C}$ in the present experiment. The lower temperature is expected to reduce the source strength by a factor of between 2 and 3. The temperature of the snow in which PNT was detected in the former experiment may also have been a bit colder than $-7^{\circ} \mathrm{C}$, and we failed to detect it when the snow was warmer than $-5^{\circ} \mathrm{C}$. Evidently, the sensitive temperature dependence of PNT source strength and retention slow its diffusion under isothermal conditions. This seems likely to be a very general phenomenon rather than unique to PNT.

We also did not detect nitrate in any of the snow samples, but this may be because concentrations were below the instrumental detection limit. Because of its high vapor pressure, we expected nitric acid to volatilize and diffuse readily through the snow, but if nitrate concentrations were below $20 \mu \mathrm{g} / \mathrm{L}$, they would have been undetected.

Attempts to determine formaldehyde likewise proved frustrating. The problem was not in failure to detect, however, but in unexpected contamination. Unfortunately, the original ice used to make the snow for the column, which was not analyzed until after the experiment, was contaminated. Similar amounts were also found in all column samples, which precludes drawing any conclusion except that the results are not inconsistent with formaldehyde diffusion through the column. A definitive result must await further experimentation. Analysis of several other batches of lab Milli-Q-purified water also had varying amounts of contamination. One sample of well water from a local source was analyzed and revealed undetectable levels of formaldehyde.

Before future experiments are conducted, potential sources of laboratory contamination other than water, such as exposure to contaminated lab air, must also be ruled out. Indoor air generally contains more formaldehyde than outdoors due to degassing of materials containing formaldehyde in a confined space. Since formaldehyde occurs ubiquitously in the environment it will probably prove im-

possible to completely eliminate this source of contamination; however, it should be possible to do the experiment by minimizing exposure to sources of contamination and, if necessary, by increasing the formaldehyde source strength. 
Figure 1 shows the concentration profile for $\mathrm{HCl}$ at the end of seven days. The profile is atypical in that, although the gas has permeated through the entire column, the concentrations behind the front decrease regularly. With a constant source, uniform concentrations behind the front would be expected. The simplest explanation for this result is that the source did not remain constant over time but became depleted. This is prone to happen with unstirred liquid solution sources such as used here, and would be exacerbated by the restricted geometry of the source, because of the mismatch between the rates of gas phase vs. liquid phase diffusion. Diffusion coefficients of solutes are roughly four orders of magnitude higher in air than in aqueous solutions. This can cause depletion of the surface layer of the source and proportionately reduced solute vapor flux when diffusion through the porous medium is as rapid as it was here. Rapid diffusion of $\mathrm{HCl}$ through the snow column was not anticipated, as the literature suggested retention by the ice surface would be more efficient (Diehl et al. 1995, Domine and Thibert 1995).

HCl Diffusion in Snow

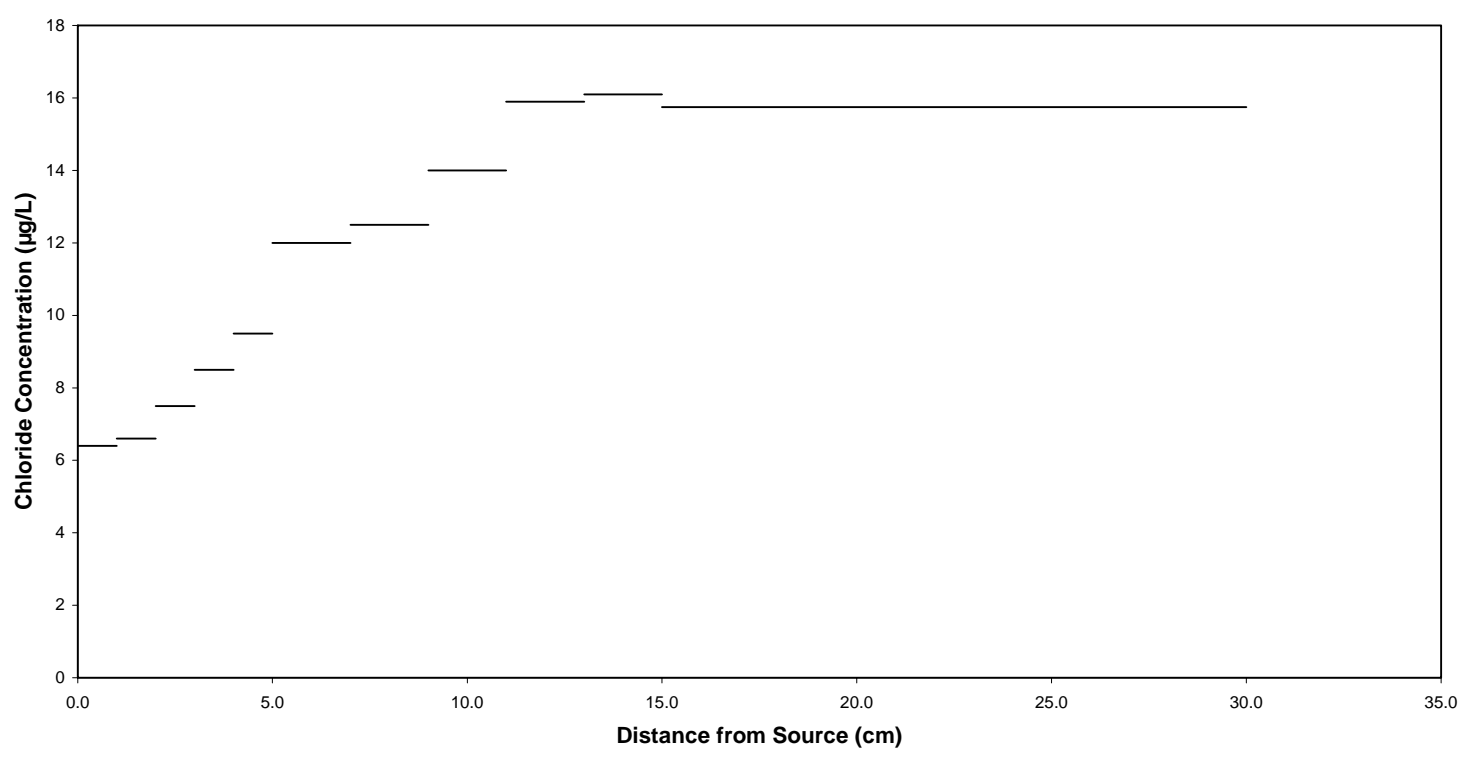

Figure 1. Chloride concentration in snow versus distance from the source $(\mathrm{HCl})$. The total length of the snow column was $30 \mathrm{~cm}$.

One might ask why the $\mathrm{HCl}$ doesn't diffuse back through the snow column. It does. Because diffusion occurs in both directions (it actually occurs in three dimensions, but the column wall restricts radial movement), $\mathrm{HCl}$ must have 
diffused backward out of the snow once the source became depleted. The lower concentrations closer to the source probably reflect this as the $\mathrm{HCl}$ diffused out of the snow and possibly repartitioned with solutions in vials of the other sources. Once the $\mathrm{HCl}$ became depleted in its source vial, the solutions in the other vials became sinks for $\mathrm{HCl}$ in the headspace and the snow.

Since the diffusion front passed completely through the column we cannot calculate an exact diffusivity of $\mathrm{HCl}$ for the experiment. We can estimate a minimum value, however, assuming the following equation applies:

$$
r=(2 D t)^{1 / 2}
$$

where $r$ is the distance of the front from the source at the end of the experiment, $D$ is the effective diffusivity or diffusion coefficient, and $t$ is time. In this case $r>30 \mathrm{~cm}$ and $t=5.83 \times 10^{5} \mathrm{~s}$ (6.75 days). Solving for $D$ we obtain a value of $D>7.7 \times 10^{-4} \mathrm{~cm}^{2} / \mathrm{s}$. This calculation shows why the $\mathrm{HCl}$ flux through the column was limited by mass transfer in the source solution. Diffusivity of $\mathrm{HCl}$ in water at $-7^{\circ} \mathrm{C}$ is expected to be no more than $10^{-5} \mathrm{~cm}^{2} / \mathrm{s}$ (Thibodeaux 1979). Since this is about two orders of magnitude less than its minimum estimated diffusivity in the snow column, it is easy to see why such a mass transfer limitation occurred.

Diffusion of gases in porous media is retarded relative to their diffusion in air by sorption on the media and tortuosity effects. We estimate the effect of tortuosity by assuming spherical geometry of the snow particles and additivity with respect to the two volume fractions, the air-filled voids, and the particle fraction. If we denote these by $V_{\mathrm{v}}$ and $\rho_{\mathrm{s}}$, the tortuosity factor would be just $V_{\mathrm{v}}+\rho_{\mathrm{s}}(\mathrm{pi} / 2)$. The measured bulk density of the snow was $0.38 \mathrm{~g} / \mathrm{cm}^{3}$. Therefore an estimate of tortuosity for the experiment is $0.62+0.38(\mathrm{pi} / 2)=1.22$. This is probably a minimum estimate due to the crude assumptions, but seems in reasonable agreement with values reported for other porous media (Thibodeaux 1979).

It was of interest to estimate a sorption coefficient for $\mathrm{HCl}$ on snow. In principle the bulk sorption coefficient can be determined from the effective diffusivity and tortuosity. We can't do this since we don't have a definite value for the diffusivity, but we can estimate a maximum value by assuming that $r=30 \mathrm{~cm}$, i.e., the length of the snow column. The molecular diffusivity of $\mathrm{HCl}$ in air at $-7^{\circ} \mathrm{C}$ was estimated as $0.14 \mathrm{~cm}^{2} / \mathrm{s}$ from reported values for other compounds of similar molecular weight at $0^{\circ} \mathrm{C}$ (Thibodeaux 1979; the lower temperature should have negligible effect). We divide this by the tortuosity to obtain a theoretical diffusivity for $\mathrm{HCl}$ in the snow column in the absence of adsorption. 
Our estimated unretarded diffusivity is then about $0.11 \mathrm{~cm}^{2} / \mathrm{s}$. An equation for retarded diffusion in porous media is

$$
R=D_{\mathrm{e}} / D_{\mathrm{r}}=1+\left(\rho_{\mathrm{s}} K_{\mathrm{b}} / V_{\mathrm{v}}\right)
$$

where $D_{\mathrm{e}}$ is the effective diffusivity without retardation, $D_{\mathrm{r}}$ is the retarded diffusivity, $>7.7 \times 10^{-4} \mathrm{~cm}^{2} / \mathrm{s}, \rho_{\mathrm{s}}$ is now the bulk density of the snow in $\mathrm{g} / \mathrm{cm}^{3}, V_{\mathrm{v}}$ is the void fraction in $\mathrm{mL} / \mathrm{cm}^{3}$, and $K_{\mathrm{b}}$ is the bulk sorption coefficient and has dimensions of mL/g. Rearranging in terms of $K_{\mathrm{b}}$ we have

$$
K_{\mathrm{b}}=(R-1) V_{\mathrm{v}} / \rho_{\mathrm{s}} \text {. }
$$

Substituting the above values gives $K_{\mathrm{b}}<140 \mathrm{~mL} / \mathrm{g}$.

An alternative expression for sorption coefficient is in terms of surface area. To do this we just divide $K_{\mathrm{b}}$ by the surface area of the snow particles in $\mathrm{cm}^{2} / \mathrm{g}$. We don't have precise knowledge of this but can estimate it from the sieve sizes used to prepare the snow and assuming spherical geometry of the particles. For the sieve openings we used the particles range from 0.425 to $0.850 \mathrm{~mm}$ in diameter. This gives a range of specific surface areas of 79 to $158 \mathrm{~cm}^{2} / \mathrm{g}$. For estimation purposes we use the mean or $120 \mathrm{~cm}^{2} / \mathrm{g}$ and estimate a surface areanormalized sorption coefficient as $K_{\mathrm{s}}<1.2 \mathrm{~cm}$ (actually $\mathrm{cm}^{3}$ air $/ \mathrm{cm}^{2}$ ice). This is the more meaningful measure if $\mathrm{HCl}$ is adsorbed on the ice surface rather than dissolved in the bulk.

Actually the maximum concentration measured in the current experiment of approximately $16 \mathrm{ng} / \mathrm{mL}$ represents only $1.3 \times 10^{-6} \mathrm{~g} / \mathrm{m}^{2}$, which is at most $1 \%$ of monolayer coverage. Thus we have no reason to infer sorption into the bulk or postulate uptake into a liquid-like surface layer, in agreement with others (Domine et al. 1995).

Of interest, and as a check on the reasonableness of the above calculation, we can back-calculate the minimum $\mathrm{HCl}$ vapor concentration that should have been obtained in the column. Since $K_{\mathrm{b}}=C_{\mathrm{b}} / C_{\mathrm{a}}=140 \mathrm{~mL} / \mathrm{g}$, where $C_{\mathrm{b}}$ and $C_{\mathrm{a}}$ are the respective $\mathrm{HCl}$ concentrations in bulk ice and air, we can solve for $C_{\mathrm{a}}$. We get $C_{\mathrm{a}}=1.1 \times 10^{-9} \mathrm{~g} / \mathrm{mL}$ or, in terms of pressure, $5.0 \times 10^{-5}$ torr. This appears to be too high based on available experimental data and recent fitting models (Miller 1983, Luo et al. 1995). The model supports a partial pressure for $\mathrm{HCl}$ in equilibrium with $3.7 \mathrm{wt} \% \mathrm{HCl}$ in water at $-7^{\circ} \mathrm{C}$ of $\sim 1.0 \times 10^{-6}$ torr.

However, if the model value is correct, $K_{\mathrm{b}}$ becomes $7.3 \times 10^{3} \mathrm{~mL} / \mathrm{g}$ and $D$, $2.5 \times 10^{-5} \mathrm{~cm}^{2} / \mathrm{s}$. At this diffusivity $\mathrm{HCl}$ should have permeated only to about 5 
$\mathrm{cm}$ in the column instead of all the way through. Resolution of this discrepancy must await future experiments. It is conceivable that the other species, namely $\mathrm{HNO}_{3}$ and formaldehyde, interfered with sorption of $\mathrm{HCl}$ on the snow. We note that the partial pressure of $\mathrm{HNO}_{3}$ under the experimental conditions (estimated according to Luo et al. 1995) would have been nearly an order of magnitude higher than that of $\mathrm{HCl}$, so it may have competed for sorption sites on the ice surface. We anticipate follow-up experiments in which only one species will be present at a time, and will attempt to measure its actual partial pressure experimentally. This is especially important for these strong acids in water as their activities, i.e., partial pressures, are highly concentration-dependent. 


\section{ENVIRONMENTAL IMPLICATIONS}

Although this work is preliminary, the rapid diffusion of $\mathrm{HCl}$ observed in snow at $-7^{\circ} \mathrm{C}$ suggests that this and possibly other mineral acids may be rapidly redistributed and lost from seasonal snowpacks. This might also explain why some acid anions are lost on storage of snow samples (Cragin and McGilvary 1995). In nature, temperature gradients tend to drive contaminants upward through snowpacks (Hogan and Leggett 1995) where concentration gradients can return them to the atmosphere by diffusion and convection. Thus, one should be cautious in interpreting measurements of potentially volatile species in seasonal snows or in polar firn, until their integrity is better established. 


\section{REFERENCES}

Cragin, J.H., and W.R. McGilvary (1995) Can inorganic chemical species volatilize from snow? Biogeochemistry of Seasonally Snow-Covered Catchments (K.A. Tonnessen, M.W. Williams, M. Tranter, Ed). Wallingford, UK: IAHS Press, International Association of Hydrological Sciences Publication No. 228, p. 11-16.

Diehl, K., S.K. Mitra, and H.G. Pruppacher (1995) A laboratory study of the uptake of $\mathrm{HNO}_{3}$ and $\mathrm{HCl}$ vapor by snow crystals and ice spheres at temperatures between 0 and $-40^{\circ}$ C. Atmospheric Environment, 29(9): 975-981.

Domine, F., and E. Thibert (1995) Relationship between atmospheric composition for $\mathrm{HCl}$ and $\mathrm{HNO}_{3}$. Atmospheric Environment, 29(9): 3-10.

Domine, F., E. Thibert, E. Silvente, M. Legrand, and J-L. Jaffrezo (1995) Determining past atmospheric $\mathrm{HCl}$ mixing ratios from ice core analyses. Journal of Atmospheric Chemistry, 21: 165-186.

Hogan, A., and D. Leggett (1995) Soil-to-snow movement of synthetic organic compounds in natural snowpack. Journal of Atmospheric Chemistry, 21: 97-105.

Hogan, A.W., S. Barnard, D. Wolfe, M. DuBois, and A.M. Pitaniello (1985) Chemical migration in mid-latitude snowpack. In Proceedings, Eastern Snow Conference, 6-7 June, Montréal, Quebec, p. 243-254.

Iribarne, J.V., and T. Pyshnov (1990) The effect of freezing on the composition of supercooled droplets-I. Retention of $\mathrm{HCl}, \mathrm{HNO}_{3}, \mathrm{NH}_{3}$, and $\mathrm{H}_{2} \mathrm{O}_{2}$. Atmospheric Environment, 24A(2): 383-387.

Luo, B., K.S. Carslaw, T. Peter, and S.L. Clegg (1995) Vapour pressures of $\mathrm{H}_{2} \mathrm{SO}_{4} / \mathrm{HNO}_{3} / \mathrm{HCl} / \mathrm{HBr} / \mathrm{H}_{2} 0$ solutions to low stratospheric temperatures. Geophysical Research Letters, 22(3): 247-250.

Miller, E. (1983) Vapor-liquid equilibria of water-hydrogen chloride solution below $0^{\circ}$ C. Journal of Chemical Engineering Data, 28: 363-367.

Thibodeaux, L.J. (1979) Chemodynamics. New York: John Wiley and Sons, Inc. 


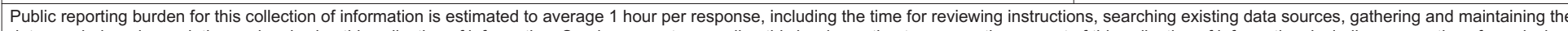

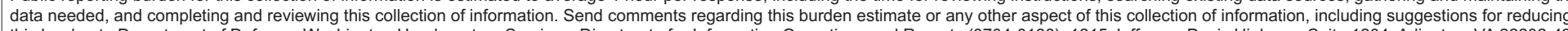

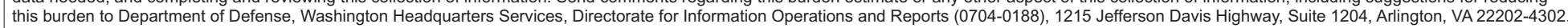

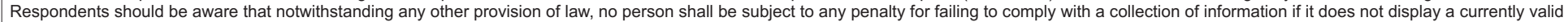
OMB control number. PLEASE DO NOT RETURN YOUR FORM TO THE ABOVE ADDRESS.
1. REPORT DATE (DD-MM-YY)
2. REPORT TYPE
3. DATES COVERED (From - To)

November 2003

Technical Report

4. TITLE AND SUBTITLE

A Preliminary Investigation of Diffusion

5a. CONTRACT NUMBER

of Volatile Atmospheric Acids in Snow

5b. GRANT NUMBER

5c. PROGRAM ELEMENT NUMBER

6. AUTHOR(S)

5d. PROJECT NUMBER

James H. Cragin and Daniel C. Leggett

5e. TASK NUMBER

5f. WORK UNIT NUMBER

7. PERFORMING ORGANIZATION NAME(S) AND ADDRESS(ES)

8. PERFORMING ORGANIZATION REPORT

U.S. Army Engineer Research and Development Center

Cold Regions Research and Engineering Laboratory

72 Lyme Road

ERDC/CRREL TR-03-22

Hanover, NH 03755-1290

9. SPONSORING/MONITORING AGENCY NAME(S) AND ADDRESS(ES)

10. SPONSOR / MONITOR'S ACRONYM(S)

U.S. Army Corp of Engineers

Washington, DC 20314-1000

11. SPONSOR / MONITOR'S REPORT NUMBER(S)

\section{DISTRIBUTION / AVAILABILITY STATEMENT}

Approved for public release; distribution is unlimited.

Available from NTIS, Springfield, Virginia 22161.

13. SUPPLEMENTARY NOTES

\section{ABSTRACT}

A preliminary coldroom experiment was conducted to determine the diffusion rate of several reactive atmospheric chemical contaminants in snow at $-7^{\circ} \mathrm{C}$. These species included formaldehyde, p-nitrotoluene (PNT), $\mathrm{HNO}_{3}$, and $\mathrm{HCl}$. Because of detection or contamination problems we could not quantify diffusion rate for formaldehyde, $\mathrm{PNT}$, or $\mathrm{HNO}_{3}$. However, the diffusivity of $\mathrm{HCl}$ in $\mathrm{snow}\left(\rho=0.38 \mathrm{~g} / \mathrm{cm}^{3}\right)$ was found to be $>7.7 \times 10^{-4} \mathrm{~cm}^{2} / \mathrm{s}$. This is about two orders of magnitude greater than hitherto expected and suggests that $\mathrm{HCl}$ may be rapidly redistributed or lost from seasonal snowpacks. Thus, one should be cautious in interpreting temporal records of $\mathrm{HCl}$ and other volatile species in seasonal or polar snowpacks, until their integrity is better established.

\begin{tabular}{|lll}
\hline 15. SUBJECT TERMS & Diffusion & Ice core records \\
& Hydrochloric acid & Snow
\end{tabular}

\begin{tabular}{|c|c|c|c|c|c|}
\hline \multicolumn{3}{|c|}{ 16. SECURITY CLASSIFICATION OF: } & \multirow{2}{*}{$\begin{array}{l}\text { 17. LIMITATION OF } \\
\text { OF ABSTRACT }\end{array}$} & \multirow{2}{*}{$\begin{array}{l}\text { 18. NUMBER } \\
\text { OF PAGES }\end{array}$} & \multirow{2}{*}{\begin{tabular}{|l|} 
19a. NAME OF RESPONSIBLE PERSON \\
19b. TELEPHONE NUMBER (include area code)
\end{tabular}} \\
\hline a. REPORT & b. ABSTRACT & c. THIS PAGE & & & \\
\hline $\mathrm{U}$ & $\mathrm{U}$ & $\mathrm{U}$ & $\mathrm{U}$ & 16 & \\
\hline
\end{tabular}

